\title{
Integração de dados quantitativos e multicategóricos na determinação da divergência genética entre acessos de cafeeiro
}

\author{
Felipe Lopes da Silva $\left({ }^{1 *}\right)$; David Carlos Ferreira Baffa ( $\left.{ }^{(}\right)$; Antonio Carlos Baião de Oliveira (2,3); \\ Antonio Alves Pereira ( $\left.{ }^{3}\right)$; Vitor Santos Bonomo (') \\ (1) Universidade Federal de Viçosa (UFV), Departamento de Fitotecnia, 36571-000 Viçosa (MG), Brasil. \\ (2) Empresa Brasileira de Pesquisa Agropecuária, Embrapa Café, 70770-901 Brasília (DF), Brasil. \\ (3) Empresa de Pesquisa Agropecuária de Minas Gerais, Unidade Regional da Zona da Mata, Campus UFV, \\ 36571-000 Viçosa (MG), Brasil. \\ $\left({ }^{*}\right)$ Autor correspondente: felipe.silva@ufv.br
}

Recebido: 18/out./2012; Aceito: 21/ago./2013

\begin{abstract}
Resumo
Foi realizada estratégia de integração dos dados quantitativos e multicategóricos para avaliação da divergência genética entre 88 acessos de Coffea arabica. Avaliaram-se 12 características quantitativas (nota total da qualidade sensorial da bebida; peso de três litros de "café da roça"; peso de três litros de "café da roça" com 11\% de umidade; porcentagem de café beneficiado a partir de três litros de "café da roça" com 11\% de umidade; peso de três litros de café beneficiado com 11\% de umidade; total de frutos de "café da roça" em um litro; porcentagem de frutos secos, passas, cereja, verde-cana e verdes em um litro de "café da roça”; e porcentagem de frutos com lojas vazias em um litro de “café da roça”) e seis características multicategóricas relacionadas à qualidade sensorial da bebida (doçura, acidez, corpo, sabor, retrogosto e aspecto geral). Baixa divergência genética foi encontrada entre os acessos considerando as características quantitativas e multicategóricas isoladamente. No entanto, com a conversão dos dados quantitativos em multicategóricos, a integração de características de diferentes naturezas favoreceu a melhor visualização da divergência genética entre os acessos avaliados, devido ao maior número de grupos formados em comparação ao agrupamento para cada conjunto de características.
\end{abstract}

Palavras-chave: Coffea arabica L., análise multivariada, banco de germoplasma.

\section{Integration of quantitative and multicategorical data in determining the genetic divergence among accessions of coffee trees}

\begin{abstract}
The strategy of integrating quantitative and multicategorical data was performed to evaluate genetic divergence among 88 accessions of Coffea arabica. Twelve quantitative traits were evaluated: total score of cup quality; weight of $3 \mathrm{~L}$ of "farm coffee"; grain yield; weight of $3 \mathrm{~L}$ of "farm coffee" with $11 \%$ moisture; weight of $3 \mathrm{~L}$ of processed coffee with $11 \%$ moisture; total "farm coffee" fruit in $1 \mathrm{~L}$; percentage of dry grains, overripe grains, cherry grains, green-cane grains and green grains in $1 \mathrm{~L}$ of "farm coffee"; percentage of fruits with empty-locus in $1 \mathrm{~L}$ of "farm coffee". Six multicategorical traits related to cup quality (sweetness, acidity, body, taste, after taste, and general aspect) were also evaluated. Low genetic divergence among accessions was found when the analysis of quantitative and multicategorical data was taken individually. However, the integration of the traits favored a better visualization of genetic divergence among the evaluated accessions when the quantitative data were converted into multicategorical ones. This occurred because of the increased number of groups formed when the integration strategy was used.
\end{abstract}

Key words: Coffea arabica L., multivariate analysis, germplasm bank.

\section{INTRODUÇÃO}

O uso do germoplasma local como fonte de matéria-prima para o melhoramento de qualquer espécie é uma alternativa promissora, sobretudo para a obtençáo de genótipos produtivos, adaptados e resistentes aos principais estresses bióticos da cultura (SouzA, 2005). Assim, a caracterização e o estudo da divergência genética entre os acessos do banco de germoplasma contribuem para o aumento da eficiência na seleção de genitores no programa de melhoramento genético.

A estatística multivariada tem sido amplamente utilizada para quantificar a divergência genética, sendo uma análise que permite integrar as múltiplas informaçôes de um conjunto de caracteres extraídos das unidades experimentais, oferecendo maior oportunidade de escolha de genitores divergentes em programas de melhoramento (FonseCA et al., 2006). Vários métodos multivariados 
podem ser aplicados na predição da divergência genética. A escolha do método mais adequado deve ser realizada em função da precisão desejada, da facilidade de análise e da forma como os dados foram obtidos (CRUZ et al., 2004).

Segundo Cruz et al. (2011), quando o estudo de diversidade genética é feito a partir de vários tipos de variáveis, podem ser recomendadas diferentes estratégias de análise, como a conversão de todas as variáveis em um único padrão, por exemplo, transformação das variáveis quantitativas em multicategóricas.

Estudos foram realizados com o objetivo de integrar dados de diferente natureza para a determinaçáo da divergência genética entre acessos de diversas culturas, demonstrando haver diferentes estratégias para essa integração (Alves et al., 2013; Martins et al., 2011; SUdrÉ et al., 2006).

Diante do exposto, o objetivo deste trabalho foi avaliar a divergência genética, por meio de procedimentos multivariados, entre 88 acessos de Coffea arabica pertencentes ao Banco de Germoplasma de Coffea spp. da Empresa de Pesquisa Agropecuária de Minas Gerais (EPAMIG), integrando dados quantitativos e multicategóricos.

\section{MATERIAL E MÉTODOS}

O Banco de Germoplasma de Coffea spp. da EPAMIG foi implantado em 2004 na Fazenda Experimental da EPAMIG, em Patrocínio, Minas Gerais. Os acessos foram implantados sob o delineamento experimental em blocos casualizados em duas repetiçôes. As parcelas experimentais foram constituídas de 10 plantas com espaçamento $3,5 \times 1 \mathrm{~m}$. Contudo, neste trabalho foi possível avaliar apenas uma repetição do banco de germoplasma.

A seleção dos acessos estudados foi feita por ocasião da colheita 2010, com base em alta carga pendente e elevado vigor vegetativo apresentados pelos cafeeiros. Foram selecionados 88 acessos, conforme apresentado na Tabela 1.

Foram avaliadas 12 características quantitativas e seis multicategóricas. As características quantitativas estudadas foram: nota total da qualidade sensorial da bebida; peso de três litros de "café da roça"; peso de três litros de "café da roça" com $11 \%$ de umidade; porcentagem de café beneficiado a partir de três litros de "café da roça" com 11\% de umidade; peso de três litros de café beneficiado com $11 \%$ de umidade; total de frutos de "café da roça" em um litro; porcentagem de frutos secos, passas, cereja, verde-cana e verdes em um litro de "café da roça"; e porcentagem de frutos com lojas vazias em um litro de "café da roça". As características multicategóricas avaliadas referiram-se à análise sensorial da qualidade de bebida, considerando: doçura, acidez, corpo, sabor, retrogosto e aspecto geral, com notas variando de 0 a 10. Para as avaliaçóes da análise sensorial da qualidade de bebida foram colhidas amostras, em cada parcela experimental, de 30 litros de frutos apenas no estádio de "café cereja". A análise sensorial da qualidade de bebida das amostras foi realizada segundo os critérios utilizados pela Brazil Specialty Coffee Association (BSCA).

Os valores médios de cada característica foram utilizados para a realização da análise de divergência genética para cada conjunto de dados, quantitativos ou multicategóricos. Como medida de dissimilaridade, para as características quantitativas, a distância Euclidiana média padronizada foi utilizada. Já para as características multicategóricas, utilizou-se como medida de dissimilaridade o complemento aritmético do índice de coincidência simples. Para o agrupamento dos acessos utilizou-se a técnica de otimização proposta por Tocher, apresentada em Cruz et al. (2011).

$\mathrm{Na}$ análise da divergência genética envolvendo a integração das 18 características, a estratégia utilizada foi a conversão dos dados quantitativos em multicategóricos, visando a obtenção de uma única matriz de dissimilaridade que contemplasse todas as características, independentemente de sua natureza. Os dados quantitativos foram codificados em número de classes pré-definido, utilizando a divisão equitativa da amplitude (DEA). Nessa estratégia, as médias foram agrupadas em 2, 3, 4, 5, 6, 7, 8, 9 e 10 classes.

Após as conversóes, nove matrizes de dissimilaridade foram obtidas, utilizando-se como medida de dissimilaridade o complemento aritmético do índice de coincidência simples. Essas matrizes foram comparadas, por meio do teste $\mathrm{Z}$ de Mantel, à matriz de dissimilaridade obtida para as características quantitativas, na qual foi utilizada como medida de dissimilaridade a distância Euclidiana média padronizada, visando estabelecer o número de classes mais adequado.

Uma vez estabelecido o melhor número de classes para a conversão dos dados quantitativos em multicategóricos, realizou-se o estudo da divergência genética entre os acessos considerando-se todos os caracteres em uma única análise de diversidade. Para essa análise utilizou-se a técnica de otimizaçáo proposta por Tocher, apresentada em CRUz et al. (2011), a partir do complemento aritmético do índice de coincidência simples na obtenção da matriz de dissimilaridade.

Todas as análises estatísticas foram realizadas com o auxílio do programa computacional GENES (CRUZ, 2006; 2008).

\section{RESULTADOS E DISCUSSÃO}

As medidas de dissimilaridade genética, para os dados quantitativos, estimadas pela distância Euclidiana média padronizada entre os pares de acessos (dados não apresentados), identificaram os acessos 13 (Bourbon Amarelo) e 14 (Sumatrão Ponta Roxa) como os mais similares e os acessos 29 (Pacamara) e 45 (BE 5 Wush-Wush x Híbrido Timor) como os mais dissimilares. Coincidentemente, o acesso 13 (Bourbon Amarelo) destacou-se como o mais similar de todos, em razão da menor distância média entre os pares de distâncias dos 
Tabela 1. Acessos do Banco de Germoplasma de Coffea spp. da EPAMIG, Patrocínio, 2010

\begin{tabular}{|c|c|c|c|}
\hline $\begin{array}{l}\mathbf{N}^{\circ} \text { do } \\
\text { acesso }\end{array}$ & Designação dos acessos & $\begin{array}{l}\mathrm{N}^{\circ} \text { do } \\
\text { acesso }\end{array}$ & Designação dos acessos \\
\hline 1 & Bourbon Amarelo & 45 & BE 5 Wush-Wush x Híbrido Timor \\
\hline 2 & Bourbon Vermelho & 46 & BE 5 Wush-Wush $\times$ Híbrido Timor \\
\hline 3 & Bourbon Amarelo & 47 & BE 5 Wush-Wush x Híbrido Timor \\
\hline 4 & Bourbon Vermelho & 48 & Bourbon N 39 x Híbrido Timor \\
\hline 5 & Bourbon Vermelho & 49 & Bourbon N 39 x Híbrido Timor \\
\hline 6 & Bourbon Vermelho & 50 & Bourbon N 197 x Híbrido Timor \\
\hline 7 & Bourbon Vermelho & 51 & Bourbon N 197 x Híbrido Timor \\
\hline 8 & Bourbon Amarelo & 52 & S 4 Agaro x Híbrido Timor \\
\hline 9 & Bourbon Amarelo & 53 & S 4 Agaro x Híbrido Timor \\
\hline 10 & Bourbon Amarelo & 54 & Dilla \& Alghe $x$ Híbrido Timor \\
\hline 11 & Bourbon Vermelho & 55 & KP 423 UFV 163-04 \\
\hline 12 & Bourbon Vermelho & 56 & K 7 IAC 1151-2 c1003 UFV 165-04 \\
\hline 13 & Bourbon Amarelo & 57 & KP 423 UFV 182-04 \\
\hline 14 & Sumatrão Ponta Roxa & 58 & Caturra Vermelho x DK $1 / 6$ \\
\hline 15 & Sumatrão Ponta Roxa & 59 & Caturra Amarelo x CIFC H358/5 \\
\hline 16 & Sumatra Palma & 60 & Caturra Amarelo x CIFC H358/5 \\
\hline 17 & Mundo Novo Purpuracens & 61 & CIFC H 310/1 x Mundo Novo \\
\hline 18 & Mundo Novo Amarelo & 62 & Bourbon $43 / 7 \times$ RP $13 \times$ CIFC H 264 \\
\hline 19 & Planta Desconhecida & 63 & Caturra Vermelho x S 333 \\
\hline 20 & Icatu Amarelo IAC 3282 & 64 & Caturra Vermelho x S 333 \\
\hline 21 & Café Brasil & 65 & Caturra Vermelho x S 795 \\
\hline 22 & Maragogipe Amarelo & 66 & Catuaí SH2 SH3 \\
\hline 23 & Maragogipe Vermelho & 67 & Mundo Novo x CIFC H 288/4 \\
\hline 24 & Caturra Vermelho & 68 & Sarchimor UFV 349-04 \\
\hline 25 & Caturra Amarelo & 69 & Sarchimor UFV 350-39 \\
\hline 26 & Caturra Amarelo Colombiano & 70 & Obatã IAC 1669-20 \\
\hline 27 & Caturra Amarelo & 71 & Cavimor UFV 357-04 \\
\hline 28 & Caturra Vermelho & 72 & Cavimor UFV 357-08 \\
\hline 29 & Pacamara & 73 & Cavimor UFV 357-22 \\
\hline 30 & Obatã Tardio & 74 & Catimor UFV 355-18 \\
\hline 31 & Obatã Amarelo & 75 & Catimor UFV 390-52 \\
\hline 32 & Híbrido de Timor UFV 376-52 & 76 & Catimor UFV 395-02 \\
\hline 33 & Híbrido de Timor UFV 376-01 & 77 & Catimor MS \\
\hline 34 & Híbrido de Timor UFV 427-15 & 78 & Catimor PI 09 \\
\hline 35 & Híbrido de Timor UFV 428-04 & 79 & Catimor PI 04 \\
\hline 36 & Híbrido de Timor UFV 437-10 & 80 & Catimor PI 07 \\
\hline 37 & Híbrido de Timor UFV 439-02 & 81 & Catimor PI 11 \\
\hline 38 & Híbrido de Timor UFV 439-03 & 82 & Bourbon Vermelho \\
\hline 39 & Híbrido de Timor UFV 441-04 & 83 & Amarelo de Botucatu \\
\hline 40 & Híbrido de Timor UFV 443-03 & 84 & Sumatra Fruto Alaranjado \\
\hline 41 & Mundo Novo x S795 UFV 315-04 & 85 & Mundo Novo Amarelo \\
\hline 42 & Mundo Novo x S795 UFV 335-04 & 86 & Mundo Novo I MP 376-4 \\
\hline 43 & K 7 x Híbrido Timor UFV 452-30 & 87 & Mundo Novo I LCP 379-19 \\
\hline 44 & H 66 x Híbrido Timor UFV 372-11 & 88 & Mundo Novo II CP 388-17-16 \\
\hline
\end{tabular}

quais esse acesso fazia parte, e o acesso 45 (BE 5 Wush-Wush x Híbrido Timor), como o mais dissimilar de todos, pois foi o de maior distância média entre os pares de distâncias dos quais esse acesso fazia parte.

Já para os dados multicategóricos, os valores das medidas de dissimilaridade genética estimadas pelo complemento aritmético do índice de coincidência simples, entre os pares de acessos (dados não apresentados), identificaram inúmeros pares de acessos como sendo similares e dissimilares. Contudo, o acesso 82 (Bourbon Vermelho) destacou-se como o mais similar de todos, e o acesso 1 (Bourbon Amarelo) como o mais dissimilar de todos, pelas mesmas razóes apresentadas anteriormente.

Mediante a análise de agrupamento pelo método de otimização de Tocher para as características quantitativas, apresentado em CRUz et al. (2011), os 88 acessos foram separados em 19 grupos (Tabela 2). 
Tabela 2. Agrupamento de 88 acessos do Banco de Germoplasma de Coffea spp. da EPAMIG pelo método de otimização de Tocher com base na dissimilaridade dos caracteres quantitativos e multicategóricos, Patrocínio, 2010

\begin{tabular}{|c|c|c|c|c|c|c|c|c|c|c|c|c|c|c|c|c|c|c|c|c|}
\hline \multirow{2}{*}{$\begin{array}{c}\text { Grupos } \\
1\end{array}$} & \multicolumn{10}{|c|}{ Dados quantitativos } & \multicolumn{10}{|c|}{ Dados multicategóricos } \\
\hline & 13 & 14 & 4 & 79 & 80 & 28 & 18 & 5 & 75 & 70 & 10 & 32 & 18 & 19 & 27 & 81 & 44 & 88 & 20 & 30 \\
\hline & 74 & 41 & 12 & 7 & 6 & 51 & 43 & 42 & 33 & 25 & 70 & 67 & 57 & 13 & 49 & 82 & 85 & 16 & 74 & 50 \\
\hline & 16 & 17 & 11 & 81 & 78 & 77 & 37 & 22 & 40 & 48 & 41 & 84 & 66 & 17 & 36 & 87 & 65 & 47 & 56 & 28 \\
\hline & 23 & 21 & 8 & 15 & 24 & 61 & 84 & 82 & 39 & 83 & 29 & 75 & 79 & 35 & 62 & 45 & 7 & 31 & 64 & 83 \\
\hline & 10 & 26 & 38 & 60 & 76 & 59 & 34 & & & & 23 & 53 & 80 & 15 & 25 & 54 & 59 & 55 & & \\
\hline 2 & 67 & 68 & 62 & 19 & & & & & & & 8 & 43 & 3 & 12 & 61 & 52 & 9 & 21 & 73 & \\
\hline & 27 & 30 & 63 & 31 & & & & & & & 63 & 76 & 72 & 60 & 48 & 26 & 51 & 33 & 22 & \\
\hline 3 & 53 & 87 & 47 & 49 & 58 & 3 & 69 & 72 & 52 & & 46 & 69 & 68 & 5 & 40 & 42 & 4 & & & \\
\hline 4 & 1 & 50 & & & & & & & & & 37 & 58 & 2 & 24 & & & & & & \\
\hline 5 & 35 & 88 & & & & & & & & & 1 & 39 & & & & & & & & \\
\hline 6 & 44 & 56 & & & & & & & & & 38 & 78 & & & & & & & & \\
\hline 7 & 20 & 57 & 55 & & & & & & & & 11 & 14 & & & & & & & & \\
\hline 8 & 64 & 66 & 54 & & & & & & & & 71 & & & & & & & & & \\
\hline 9 & 29 & 36 & & & & & & & & & 34 & & & & & & & & & \\
\hline 10 & 73 & & & & & & & & & & 6 & & & & & & & & & \\
\hline 11 & 71 & & & & & & & & & & 77 & & & & & & & & & \\
\hline 12 & 46 & & & & & & & & & & 86 & & & & & & & & & \\
\hline 13 & 2 & & & & & & & & & & & & & & & & & & & \\
\hline 14 & 65 & & & & & & & & & & & & & & & & & & & \\
\hline 15 & 86 & & & & & & & & & & & & & & & & & & & \\
\hline 16 & 85 & & & & & & & & & & & & & & & & & & & \\
\hline 17 & 32 & & & & & & & & & & & & & & & & & & & \\
\hline 18 & 9 & & & & & & & & & & & & & & & & & & & \\
\hline 19 & 45 & & & & & & & & & & & & & & & & & & & \\
\hline
\end{tabular}

Ficaram alocados no primeiro grupo 47 acessos, o que representa, aproximadamente, $53,4 \%$ do total dos acessos caracterizados. Analisando o agrupamento dos acessos para as características multicategóricas, os 88 acessos foram separadas em 12 grupos. Ficaram alocados no primeiro grupo 48 acessos, o que representa, aproximadamente, $54,5 \%$ do total dos acessos caracterizados. Mediante os agrupamentos formados para os conjuntos de dados quantitativos e multicategóricos, pôde-se evidenciar a baixa variabilidade genética entre os acessos para as características avaliadas, principalmente devido ao fato de grande parte dos acessos estarem em apenas um grupo.

Em trabalho com subamostras de tomateiro pertencentes ao Banco de Germoplasma de Hortaliças da Universidade Federal de Viçosa, Martins et al. (2011) também encontraram número diferente de grupos e distribuição diferenciada dos acessos nos grupos quando compararam o agrupamento formado por características quantitativas, multicategóricas e moleculares.

A estimaçáo do coeficiente de correlação testado pelo teste $\mathrm{Z}$ de Mantel e pelo teste $\mathrm{t}$, entre as matrizes de dissimilaridade obtidas com base nos grupos de caracteres, quantitativos ou multicategóricos, auxiliam na determinação da discordância dos agrupamentos realizados para cada conjunto de características, sejam elas quantitativas ou multicategóricas. A estimativa da correlação foi de baixa magnitude $(0,02)$ e não significativa, evidenciando que a diversidade a partir de um conjunto de dados náo pode ser extrapolada para outro conjunto de dados de natureza diferente. A observaçáo de valores de correlação menores que 0,10 sugere que a diversidade genética obtida com base nos caracteres quantitativos náo explica a diversidade dos caracteres multicategóricos.

As análises baseadas em diversidade fenotípica ou em dados moleculares, no trabalho de Alves et al. (2013), resultaram num número semelhante de grupos indistinguíveis e numa concentração semelhante de genótipos em um único grupo. No entanto, a correlação entre a matriz de dissimilaridade de Gower e a matriz de dissimilaridade de Jaccard foi baixa.

Martins et al. (2011), ao comparar dados quantitativos e multicategóricos em tomate, encontraram valor de correlação entre as matrizes de dissimilaridade de 0,46. Koehler-Santos et al. (2003), ao avaliarem germoplasma de Citrus, não obtiveram concordância no padrão de variação quando compararam as matrizes geradas com os dados morfológicos e os marcadores microssatélites.

Valores de correlaçáo inferiores a 0,7 têm sido considerados inconsistentes, o que indica que a diversidade genética obtida com base em um conjunto de caracteres náo explica a diversidade com base em outro conjunto (RoHLf, 2000). Valores de correlação são estatisticamente significativos a $1 \%$ de probabilidade se forem superiores a 0,50 quando o número de unidades comparadas for maior do que 15 (TATineni et al., 1996). 
Isso implica que todos os dois conjuntos de caracteres foram importantes para a análise de divergência genética entre os acessos avaliados. Contudo, há necessidade de integraçáo dos dados quantitativos e multicategóricos para a melhor estimação da divergência genética entre os acessos avaliados.

A partir da conversão dos dados quantitativos em multicategóricos, pela estratégia do número de classes pré-definido $(2,3,4,5,6,7,8,9$ e 10) utilizando a divisão equitativa da amplitude (DEA), foram obtidas nove matrizes de dissimilaridade. As estimativas dos coeficientes de correlação entre essas matrizes e a matriz de dissimilaridade obtida a partir dos dados quantitativos originais são apresentadas na Tabela 3.

Tabela 3. Correlação entre a matriz de dissimilaridade obtida a partir dos dados quantitativos originais e as matrizes de dissimilaridade obtidas pela estratégia do número de classes predefinido e divisão equitativa da amplitude (DEA) para codificação desses dados, Patrocínio, 2010

\begin{tabular}{c|cc|} 
Estratégia & Número de classes & Correlação \\
\hline & 2 & $0,56355^{* *++}$ \\
\hline \multirow{2}{*}{ DEA } & 3 & $0,74483^{* *++}$ \\
& 5 & $0,64539^{* *++}$ \\
& 6 & $0,63884^{* *+}$ \\
& 7 & $0,58445^{* *+}$ \\
& 8 & $0,55960^{* *++}$ \\
\hline 9 & $0,52916^{* *++}$ \\
\hline 10 & $0,50252^{* *+}$ \\
\hline
\end{tabular}

${ }^{*}$ Significativo a $1 \%$ de probabilidade pelo teste $t$; ++ significativo a $1 \%$ de probabilidade pelo teste $\mathrm{Z}$ de Mantel baseado em mil simulaçōes
Dentre o número de classes pré-definidas para a conversão dos dados quantitativos em multicategóricos, apenas a codificação pela distribuição equitativa da amplitude em 3 classes (DEA-3) foi consistente, com valor de correlação maior que 0,7 , conforme preconizado por RoHLF (2000), e significativo a $1 \%$ de probabilidade, tanto pelo teste $\mathrm{t}$ quanto pelo $\mathrm{Z}$ de Mantel.

Após a determinação da melhor estratégia de codificaçãoo dos dados (DEA-3), procedeu-se ao estudo de diversidade genética com a integração dos dados quantitativos convertidos e multicategóricos. Assim, a análise de diversidade genética foi realizada considerando 18 características (12 quantitativas convertidas e seis multicategóricas).

As medidas das dissimilaridades genéticas, estimadas pelo complemento aritmético do índice de coincidência simples entre os pares de acessos (dados náo apresentados), identificaram os acessos 21 (Café Brasil) e 65 (Caturra Vermelho x $\mathrm{S}$ 795) como os mais dissimilares, sendo esse último o mais dissimilar de todos, pois foi o de maior distância média entre os pares de distâncias dos quais esse acesso fazia parte.

$\mathrm{O}$ acesso 74 se destacou como o mais similar de todos, em razão da menor distância média entre os pares de distâncias dos quais esse genótipo fazia parte. Contudo, ao obter a matriz de dissimilaridade considerando a integraçáo dos dados quantitativos convertidos em multicategóricos, verificou-se que quatro pares de genótipos foram considerados similares, visto terem apresentado os mesmos valores de dissimilaridade;

Tabela 4. Agrupamento de 88 acessos do Banco de Germoplasma de Coffea spp. da EPAMIG pelo método de otimizaçáo de Tocher a partir da integração de dados multicategóricos e quantitativos convertidos em multicategóricos pela estratégia da divisão equitativa da amplitude dos dados em três classes (DEA-3), Patrocínio, 2010

\begin{tabular}{|c|c|c|c|c|c|c|c|c|c|c|c|c|c|c|c|c|c|c|c|c|}
\hline Grupos & & & & & & & & & & ubar & ostra & & & & & & & & & \\
\hline 1 & 10 & 88 & 16 & 50 & 84 & 82 & 51 & 76 & 74 & 25 & 18 & 75 & 27 & 13 & 36 & 49 & 47 & 38 & 37 & 41 \\
\hline 2 & 21 & 23 & 62 & 7 & 28 & 61 & 17 & 22 & 48 & 4 & 6 & 14 & 42 & 11 & 43 & 79 & 5 & 40 & 80 & 78 \\
\hline 3 & 30 & 66 & 67 & 19 & 31 & 63 & 64 & & & & & & & & & & & & & \\
\hline 4 & 32 & 81 & 24 & 44 & 77 & 70 & & & & & & & & & & & & & & \\
\hline 5 & 1 & 39 & 34 & 33 & & & & & & & & & & & & & & & & \\
\hline 6 & 12 & 60 & 73 & 83 & 54 & & & & & & & & & & & & & & & \\
\hline 7 & 35 & 85 & 26 & & & & & & & & & & & & & & & & & \\
\hline 8 & 45 & 55 & 57 & & & & & & & & & & & & & & & & & \\
\hline 9 & 3 & 52 & 72 & & & & & & & & & & & & & & & & & \\
\hline 10 & 2 & 9 & 56 & & & & & & & & & & & & & & & & & \\
\hline 11 & 46 & 69 & & & & & & & & & & & & & & & & & & \\
\hline 12 & 65 & 87 & & & & & & & & & & & & & & & & & & \\
\hline 13 & 8 & 15 & & & & & & & & & & & & & & & & & & \\
\hline 14 & 59 & & & & & & & & & & & & & & & & & & & \\
\hline 15 & 86 & & & & & & & & & & & & & & & & & & & \\
\hline 16 & 68 & & & & & & & & & & & & & & & & & & & \\
\hline 17 & 58 & & & & & & & & & & & & & & & & & & & \\
\hline 18 & 20 & & & & & & & & & & & & & & & & & & & \\
\hline 19 & 53 & & & & & & & & & & & & & & & & & & & \\
\hline 20 & 71 & & & & & & & & & & & & & & & & & & & \\
\hline 21 & 29 & & & & & & & & & & & & & & & & & & & \\
\hline
\end{tabular}


são eles: 10 (Bourbon Amarelo) e 88 (Mundo Novo II CP 388-17-16); 19 (Planta Desconhecida) e 27 (Caturra Amarelo); 21 (Café Brasil) e 23 (Maragogipe Vermelho); e 23 (Maragogipe Vermelho) e 62 (Bourbon 43/7 x RP13 $x$ CIFC H 264).

$\mathrm{O}$ agrupamento dos 88 acessos pelo método de Tocher baseado em uma única matriz de dissimilaridade obtida a partir do complemento aritmético do índice de coincidência simples é apresentado na Tabela 4.

Analisando o agrupamento, os 88 acessos foram separados em 21 grupos, sendo que os grupos 1 e 2 foram formados por 20 acessos. Diante do agrupamento formado foi possível concluir que a estratégia de conversáo dos dados quantitativos em multicategóricos e a integração dos dados de diferente natureza, favoreceu a melhor visualização da divergência genética entre os acessos avaliados, devido ao maior número de grupos formados em comparação ao agrupamento para cada conjunto de características (quantitativas ou multicategóricas).

\section{CONCLUSÃO}

Baixa divergência genética é encontrada entre os acessos considerando as características quantitativas e multicategóricas isoladamente. No entanto, com a conversão dos dados quantitativos em multicategóricos, a integração de características de diferente natureza favorece a melhor visualização da divergência genética entre os acessos avaliados, devido ao maior número de grupos formados em comparação ao agrupamento para cada conjunto de características.

\section{AGRADECIMENTOS}

Ao Consórcio Pesquisa Café, à Fundação de Amparo à Pesquisa do Estado de Minas Gerais (FAPEMIG) e ao Conselho Nacional de Desenvolvimento Científico e Tecnológico (CNPq), pelo suporte financeiro ao Programa de Melhoramento Genético do Café da Empresa de Pesquisa Agropecuária de Minas Gerais.

\section{REFERÊNCIAS}

ALVES, A.A.; BHERING, L.L.; ROSADO, T.B.; LAVIOLA, B.G.; FORMIGHIERI, E.F.; CRUZ, C.D. Joint analysis of phenotypic and molecular diversity provides new insights on the genetic variability of the Brazilian physic nut germplasm bank. Genetics and Molecular Biology, v.36, p.371-381, 2013. http://dx.doi.org/10.1590/S141547572013005000033

CRUZ, C.D.; REGAZZI, A.J.; CARNEIRO, P.C.S. Modelos biométricos aplicados ao melhoramento genético.Viçosa: UFV, 2004. 480 p.

CRUZ, C.D. Programa GENES: estatística experimental e matrizes. Viçosa: UFV, 2006. 285p.

CRUZ, C.D. Programa GENES: diversidade genética. Viçosa: UFV, 2008. 278p.

CRUZ, C.D.; FERREIRA, F.M.; PESSONI, L.A. Biometria aplicada ao estudo da diversidade genética. Visconde do Rio Branco: Suprema, 2011.620p.

FONSECA, A.F.A.; SEDIYAMA, T.; CRUZ, C.D.; SAKAIYAMA, N.S.; FERRÃO, M.A.G.; FERRÃO, R.G.; BRAGANÇA S.M. Divergência genética em café conilon. Pesquisa Agropecuária Brasileira, v.41, p.599605, 2006. http://dx.doi.org/10.1590/S0100-204X2006000400008

MARTINS, F.A.; CARNEIRO, P.C.S.; SILVA, D.J.H.; CRUZ, C.D.; CARNEIRO, J.E.S. Integração de dados em estudos de diversidade genética de tomateiro. Pesquisa Agropecuária Brasileira, v.46, p.1496-1502, 2011

KOEHLER-SANTOS, P.; DORNELLES, A.L.C.; FREITAS, L.B. Characterization of mandarin citrus germplasm from Southern Brazil by morphological and molecular analyses. Pesquisa Agropecuária Brasileira, v.38, p.797-806, 2003. http://dx.doi.org/10.1590/S0100204X2003000700003

ROHLF, F.J. NTSYS-pc: numerical taxonomy and multivariate analysis system. New York: Exeter Software, 2000. 38p.

SOUZA, F.F. Divergência genética em clones de café conilon (Coffea canephora Pierre.) coletados em Rondônia. Rondônia: Embrapa Rondônia, 2005. 289p.

SUDRÉ, C.P.; CRUZ, C.D.; RODRIGUES, R.; RIVA, E.M.; AMARAL JÚNIOR, A.T.; SILVA, D.J.H.; PEREIRA, T.N.S. Variáveis multicategóricas na determinaçáo da divergência genética entre acessos de pimenta e pimentáo. Horticultura Brasileira, v.24, p.88-93, 2006. http://dx.doi.org/10.1590/S0102-05362006000100018

TATINENI, V.; CANTRELL, R.G.; DAVIS, D.D. Genetic diversity in elite cotton germoplasm determined by morphological and RAPDs. Crop Science, v.36, p.186-192, 1996. http://dx.doi.org/10.2135/cr opsci1996.0011183X003600010033x 